\title{
Los puntajes en los exámenes de matriculación se asocian sostenidamente con el desempeño futuro de los médicos de familia canadienses
}

\section{Objetivo}

Determinar si existe una relación sostenida entre el puntaje del examen de certificación de Medicina Familiar y el desempeño asistencial, y si los exámenes de matriculación médica canadiense al final de la carrera son predictores de la práctica futura en atención primaria.

\section{Diseño}

Estudio de cohorte prospectivo de 4 a 7 años de seguimiento

\section{Lugar}

Ámbito de atención primaria en Québec, Canadá.

\section{Participantes}

Cohorte de 912 médicos de familia en ejercicio, que aprobaron el examen de certificación de Medicina Familiar de Québec (QLEX).

\section{Evaluación de factores pronósticos}

Para valorar el desempeño médico se utilizaron bases de datos del sistema universal de salud de Québec (3,4 millones de pacientes).

\section{Medición de resultados principales}

Tasas (por cada 1000 personas-año) ajustados por case-mix* de: rastreo mamográfíco en mujeres elegibles, índice de continuidad de cuidados (proporción de visitas realizadas o derivadas por el médico en estudio de toda la población de pacientes), diferencia entre la tasa de prescripción por enfermedad específica (anticoagulantes, anticonvulsivantes, antidepresivos, etc) y sintomática o de bajo impacto en el proceso de enfermedad (antinflamatorios, opiáceos, complejos vitamínicos), de prescripciones contraindicadas y de interconsultas anuales a especialistas en relación a cada incremento de desvío standard (DS) del puntaje en los exámenes.

\section{Resultados principales}

Los médicos con mayores puntajes en los exámenes de matriculación médica canadiense (MCCQE) tomado al final de la carrera y de Medicina Familiar (QLEX) tenían índices más altos de rastreo mamográfíco y de continuidad del cuidado. Puntajes más altos de conocimiento farmacológico también fueron predictores de RR más bajos de prescripciones contraindicadas RR 0.88 (0.77-1.00). Estas asociaciones se sostuvieron durante los 4 a 7 años de seguimiento.

\section{Conclusiones}

Los puntajes alcanzados en los exámenes de matriculación y de certificación muestran una relación sostenida con índices del cuidado preventivo y de manejo de enfermedad aguda y crónica en atención primaria que se sostienen a lo largo de 4 a 7 años.

Fuente de financiamiento: Canadian Institutes of Health Research y fondos de investigación de Santé du Québec.

\section{Comentario}

La certificación de la competencia es un tema de amplio debate en todo el mundo, dadas las graves consecuencias que sus resultados tienen sobre el cuidado de las personas y el futuro profesional de los especialistas certificados. Existe debate acerca de cual es el mejor proceso de evaluación para determinar suficiente validez y confiabilidad, o sea, evitar la menor tasa posible de falsos positivos (aprueban el examen pero no son competentes) y negativos (son competentes pero no aprueban el examen) 1.

Este es un estudio muy importante ya que es uno de los pocos que demuestra que con este sistema de evaluación de la competencia se "predice" el futuro desempeño de los médicos de familia en la Provincia de Québec en Canadá hasta los 7 años posteriores a la evaluación. En este caso, la combinación de evaluaciones del conocimiento teórico a través de una prueba de elección de opciones múltiples y de respuesta corta, y habilidades y actitudes a través de un examen clínico objetivo y estructurado (ECOE u OSCE en inglés) permitió predecir el desempeño de los especialistas en la práctica real. Este tipo de evaluación basada en la práctica, no sólo permite evaluar competencias que con otros métodos es imposible realizar (habilidades para recolectar información, demostrar empatía, comunicar malas noticias, realizar maniobras del examen físico etc.) sino que además orienta el aprendizaje de los que deben ser evaluados hacia la adquisición de estos conocimientos más que de conocimiento fáctico, como lo hace la prueba de elección de opciones múltiples².

La mayor debilidad del estudio es que no tuvo seguimiento de los que no aprobaron la certificación aunque la correlación de los puntajes de los exámenes con los indicadores de práctica clínica mostró variar en el mismo sentido. Otro punto importante es considerar el tipo y la construcción de los indicadores utilizados para evaluar esa competencia, ya que en muchas ocasiones, los indicadores cuantitativos son insuficientes para representar un dominio tan vasto y complejo como el del desempeño profesional.

\section{Conclusión del comentador}

Este es un estudio importante ya que ofrece suficiente evidencia sobre validez predictiva de una secuencia de evaluaciones para la certificación de profesionales en base a investigar diferentes áreas del conocimiento y especialmente la práctica en condiciones "reales" a través del ECOE.

\section{Dr. Eduardo Durante [ Unidad de Medicina Familiar y Preventiva del Hospital Italiano de Buenos Aires ]}

Durante E. Los puntajes en los exámenes de matriculación se asocian sostenidamente con el desempeño futuro de los médicos de familia canadienses. Evid. actual. práct. ambul. 2005;2: 43. Comentado de: Association between licensure examination scores and practice in primary care. Tamblyn R, Abrahamowicz M, Dauphinee WD, et al. JAMA 2002; 288:3019-3026.

\section{Referencias}

1. Van der Vleuten CPM. The assessment of professional competence: developments, research and practical implications. Adv Health Sci Educ $1996 ; 1: 41-67$. 2. Van der Vleuten CPM, Swanson SM. Assessment of clinical skills with standardised patients: state of the art. Teaching Learning in Med 1990; $25: 224-9$. 